\title{
KECERDASAN SOSIAL DALAM PEMBELAJARAN KOOPERATIF PERSPEKTIF AL-QUR'AN
}

\author{
Ahmad Zain Sarnoto ${ }^{1}$ dan Siti Maria Ulfa ${ }^{2}$ \\ ${ }^{1,2}$ Institut PTIQ Jakarta \\ ${ }^{1}$ Email: ahmadzain@ptiq.ac.id, \\ ${ }^{2}$ Email: mariaulfa2005@gmail.com
}

\begin{abstract}
ABSTRAK
Penelitian ini menyimpulkan bahwa, kecerdasan sosial merupakan kemampuan seseorang untuk mengerti orang lain dan peduli terhadap lingkungan sosial. Hal ini berdasarkan dua dimensi kecerdasan sosial perspektif al-Quran yang penulis temukan yaitu dimensi perasaan (aspek afektif) dan dimensi tindakan (aspek psikomotik). Dalam dimensi perasaan (aspek afektif) terdiri atas empati dan ikhlas, sedangkan dimensi tindakan (ranah psikomotik) terdiri atas tolong- menolong, silaturahim, kepedulian dan komunikasi. Artinya al-Qur'an mendeskripsikan tentang keseimbangan antara habl ma'a Khaliqih dan habl ma'a ikhwanih. Dengan demikian, model pembelajaran kooperatif berbasis al-Quran ini dapat membantu meningkatkan kecerdasan sosial anak. Pembelajaran kooperatif merupakan model pembelajaran dengan menggunakan sistem pengelompokkan siswa, yang mempunyai latar belakang kemampuan akademik, jenis kelamin, ras, atau suku yang berbeda (heterogen). Pembelajaran kooperatif dapat membentuk keterampilan interpersonal karena ada unsur bekerjasama, saling membantu, tolong menolong dan diskusi. Hal ini berdasarkan dua indikator pembelajaran kooperatif perspektif al-Qur'an yang penulis temukan, yaitu tolong-menolong dan musyawarah. Pendekatan yang digunakan dalam penelitian ini adalah pendekatan kualitatif. Sedangkan metode yang dipakai adalah metode tafsir tematik. Adapun teknik pengumpulan data yang digunakan adalah melalui studi kepustakaan.
\end{abstract}

Kata kunci: Kecerdasan Sosial, Pembelajaran Koopertif, Al-Qur'an

\begin{abstract}
This study concluded that social intelligence is a person's ability to understand other people and care about the social environment. This is based on the two dimensions of social intelligence from the perspective of the Koran that the authors found, namely the feeling dimension (affective aspect) and the action dimension (psychomotic aspect). In the feeling dimension (affective aspect) consists of empathy and sincerity, while the action dimension (psychomotic realm) consists of helping, friendship, caring and communication. This means that the Qur'an describes the balance between habl ma'a Khaliqih and habl ma'a ikhwanih. Thus, this Quran-based cooperative learning model can help improve children's social intelligence. Cooperative learning is a learning model using a system of grouping students, who have different academic backgrounds, gender, race, or ethnicity (heterogeneous). Cooperative learning can form interpersonal skills because there are elements of working together, helping each other, helping out and discussing. This is based on the two indicators of cooperative learning in the perspective of the Qur'an that the author found, namely helping and deliberation. The approach used in this study is a qualitative approach. While the method used is a thematic interpretation method. The data collection technique used is through literature study
\end{abstract}

Keywords: Social Intelligence, Cooperative Learning, Al-Qur'an

\section{PENDAHULUAN}

Pendidikan merupakan sarana strategis yang dapat mengembangkan dan membentuk potensi siswa baik berupa intelektual (kognitif), keterampilan (psikomotor), maupun sikap 
(afektif), menurut (Sarnoto \& Andini, 2017). Dalam Islam hakikat pendidikan adalah bangunan nilai yang di dalamnya terdapat cara pandang, sikap, dan tindakan. Konsepkonsep pendidikan di rumuskan oleh pakar pendidikan Islam ialah konsep pendidikan yang diarahkan untuk pribadi-pribadi yang bertakwa kepada Allah SWT dan beramal shaleh dalam kehidupan sosial. Inilah inti atau hakikat pendidikan Islam (Sarnoto, 2019). Sebagai agama yang menekankan keseimbangan aspek spiritual dan intelektual, Islam mengajarkan kepada umatnya agar mengasah diri untuk mencapai hakikat kemanusiaan dan kehambaannya di hadapan Allah SWT. Rasullah SAW sudah memberikan contoh menjadi hamba yang benar-benar "menghamba" kepada-Nya. Karena itu, diselenggarakannya pendidikan Islam ialah agar manusia mampu menjadi pribadi-pribadi yang bertakwa secara transendental dan sosial (Rasyid, 2017).

Ada beberapa pandangan ahli tentang kecerdasan. Pandangan yang pertama dari Alfred Binet, merupakan tokoh perintis pengukuran intelegensi. Binet, menjelaskan bahwa intelegensi merupakan kemampuan mengarahkan pikiran atau mengarahkan tindakan, artinya individu mampu menetapkan tujuan untuk dicapainya (goal setting), kemampuan untuk mengubah arah tindakan bila dituntut demikian artinya individu mampu melakukan penyesuaian diri dalam lingkungan tertentu (adaptasi), dan kemampuan untuk mengkritik diri sendiri atau melakukan autokritik artinya individu mampu melakukan perubahan atas kesalahan-kesalahan yang telah diperbuatnya atau mampu mengevaluasi dirinya sendiri secara obyektif (Sarnoto \& Rahmawati, 2020).

Pendapat lain menyatakan bahwa intelegensi sebagai kumpulan atau totalitas kemampuan individu untuk bertindak dengan tujuan tertentu, berfikir secara rasional, serta menghadapi lingkungannya dengan efektif, hal ini menurut pendapat David Wechler. Sedangkan George D. Stoddard, mendefinisikan intelegensi sebagai bentuk kemampuan untuk memahami masalah-masalah yang bercirikan kesukaran, kompleks, abstrak, ekonomis, diarahkan pada suatu tujuan, mempunyai nilai sosial dan berasal dari sumbernya (menciptakan sesuatu yang baru dan lain). Tokoh lain yaitu Walters dan Gardner, mendefinisikan intelegensi sebagai suatu kemampuan atau serangkaian kemampuankemampuan yang memungkinkan individu memecahkan masalah, atau produk sebagai konsekuensi eksistensi suatu budaya tertentu (Safaria, 2005).

Kecerdasan sosial adalah kemampuan seseorang dalam menghadapi dan mereaksi situasi-situasi sosial atau kehidupan di dalam lingkungan masyarakat. Kecerdasan sosial merupakan kemampuan seseorang untuk mengerti kepada orang lain, dan juga kemampuan seseorang untuk dapat berbuat sesuatu dengan tuntutan masyarakat. Jadi, kecerdasan sosial 
adalah bukan merupakan emosi seseorang terhadap orang lain. Individu dengan kecerdasan sosial yang tinggi akan mampu berinteraksi, bergaul, atau berkomunikasi dengan orang lain secara mudah. Selain itu, seseorang yang mempunyai kecerdasan sosial yang tinggi diindikasikan bahwa seorang tersebut mampu menyesuaikan diri dalam berbagai lingkungan sosial budaya. Kecerdasan sosial yakni kemampuan seseorang dalam memahami dan mengelola sebuah hubungan sosial (Azzet, 2010).

Thorndike, psikolog Amerika Serikat, mendefinisikan bahwa kecerdasan sosial adalah the ability to understand and manage men and women, boys, and girls to act wisely in human relation. Menurut Edward Lee Thorndike, dalam Purwa Atmaja Prawira mengklasifikasikan kecerdasan menjadi tiga tipe, yaitu kecerdasan riil (concrete intelligence), kecerdasan abstrak (abstract intelligence), dan kecerdasan sosial (social intelligence) (Prawira, 2013).

Manusia adalah makhluk individu yang memiliki perbedaan antara satu orang dengan lainnya. Manusia juga memiliki derajat potensi dan latar belakang, serta historis, dan juga mempunyai harapan masa depan yang berbeda-beda. Karena adanya perbedaan tersebut, manusia dapat silih asah (saling mencerdaskan). Pembelajaran kooperatif secara sadar menciptakan interaksi yang silih asah, bisa dikatakan demikian karena sumber belajar bagi seorang peserta didik tidak hanya berasal dari guru dan buku ajar semata, akan tetapi sumber belajar bisa didapat dari sesama siswa. Istilah belajar antara sesama teman disebut dengan peer teaching (Sarnoto, 2017).

Pembelajaran kooperatif berasal dari istilah Cooperative Learning. Dalam Oxford Advanced Learner's Dictionary, menyebutkan bahwa Cooperative berarti acting together with a common purpose (Wehmeier, 2010). Beberapa arti dari cooperative disampaikan oleh Basyiruddin Usman, menurutnya cooperative didefinisikan sebagai belajar kelompok atau bekerjasama (Usman, 2002). Sedangkan ahli tokoh lain, yaitu Burton sebagaimana yang dikutip oleh Nasution, disebutkan bahwa kooperatif atau kerjasama ialah cara individu mengadakan relasi dan bekerjasama dengan individu lain untuk mencapai tujuan bersama (Nasution, 1995). Sedangkan kata learning juga mempunyai berbagai pengertian. Learning didefinisikan oleh Arthur T. Jersild, yang dikutip Syaiful Sagala, menyatakan learnig is modification of behavior through experience and training yakni pembentukan perilaku melalui pengalaman dan latihan. Selain pengertian tersebut, Arthur, juga menambahkan bahwa learning sebagai kegiatan memperoleh pengetahuan, perilaku dan keterampilan dengan cara mengolah bahan ajar (Sagala, 2003). 
Al-Qur'an merupakan mukjizat terbesar yang bersifat universal dan berlaku untuk seluruh umat manusia. Wahyu yang diturunkan kepada Nabi Muhammad SAW tersebut berisi informasi yang ditetapkan sebagai pedoman hidup manusia, kapanpun dan di manapun ia berada. Sebagai sebuah mukjizat, al-Qur'an tidak hanya sebatas bahan bacaan kendatipun membacanya akan memperoleh pahala, tetapi juga untuk dipelajari, diimani, diamalkan dan diungkap rahasia kebenarannya. Hal tersebut bertujuan untuk memperkaya cakrawala ilmu pengetahuan terhadap bukti-bukti kebesaran dan kekuasaan Allah, selain untuk membimbing kehidupan manusia, agar ia dapat memperoleh kebahagiaan di dunia dan akhirat. Islam sangat peduli dengan potensi akal pikiran manusia. Dalam al-Qur'an banyak sekali ayat-ayat yang mengisyaratkan hal ini. Berkali-kali Allah SWT menyebutkan perihal akal, orang yang berakal, serta penggunaan akal pikiran (Charisma, 1991).

Dalam al-Qur'an, terdapat informasi yang menyatakan bahwa manusia memiliki unsur-unsur yang berbeda dengan makhluk hidup lain, yaitu potensi, kemampuan belajar dan menuntut ilmu yang tidak terbatas. Namun kemampuan ini dapat mengantarkan manusia pada arah yang positif dan negatif. Manusia memiliki potensi dan kemampuan untuk menduduki tempat tertinggi di alam eksistensi, namun potensi yang ia miliki juga dapat membuatnya jatuh terjerumus ke dalam kedudukan terendah, dan bahkan lebih rendah dari kedudukan seekor binatang. Adapun manusia yang menjadi bagian dari dua kedudukan tersebut, sangat ditentukan oleh proses pembelajaran yang dijalaninya di dunia, dimana pembelajaran tersebut akan menciptakan suatu kecerdasan dalam dirinya (Faisal, 2016).

\section{METODE PENELITIAN}

Dalam penelitian ini, pendekatan yang digunakan bersifat library research (penelitian kepustakaan) atau disebut juga content analysis (analisis isi). Oleh karena itu, metode penelitian yang digunakan adalah pengumpulan data dan informasi dalam bentuk bahan yang ada di perpustakaan berupa arsip, dokumen, majalah, buku, dan materi pustaka lainnya, dengan asumsi bahan yang diperlukan dalam pembahasan ini terdapat didalamnya (Irawan, 2000).

Adapun teknis pengumpulan data yang dilakukan yaitu mencatat data-data yang diambil dari berbagai sumber dari bahan-bahan tertulis kemudian mengidentifikasi buktibukti kontekstual yaitu dengan mencari hubungan antara data dengan realitas yang penulis teliti. Pengolahan data dalam penelitian ini bersifat kualitatif maka dilakukan dengan 
analisis kritis, komparasi, serta interpretasi atas berbagai hasil penelusuran dari sumbersumber primer dan sekunder. Dengan demikian pendekatan data penelitian ini substansinya adalah kualitatif dan korelasi jaringan variabelnya juga kualitatif (Sukmadinata, 2010).

Selain merujuk berbagai sumber bacaan yang berkaitan dengan penelitian, pada pembahasan materi ini merujuk beberapa kitab tafsir yang berkaitan dengan materi tersebut dengan menggunakan metode tafsir tematik. Tafsir tematik atau juga lebih dikenal dengan tafsir maudu'i adalah pola penafsiran dengan cara memfokuskan pada satu topik yang berkaitan dengan masalah tertentu, kemudian mendefinisikan kata kunci dari permasalahan, selanjutnya mengumpulkan ayat-ayat Al-Qur'an yang terkait dengan topik tersebut baik secara lafadz maupun hukum, kemudian melihat tafsir-tafsir ayat-ayat tersebut sesuai dengan tujuan Qur'ani (Alim, 2014).

\section{PEMBAHASAN}

Dalam proses pembelajaran kooperatif, sangat ditekankan adanya sikap saling menghargai perbedaan pendapat. Dengan menggunakan model pembelajaran ini, diharapkan anak-anak nantinya setelah berkehidupan dimasyarakat akan menjadi pribadi yang dapat menghargai perbedaan pendapat yang ada di masyarakat, karena telah terbiasa dengan model pembelajaran yang diaplikasikan di sekolah dengan menggunakan model pembelajaran kooperatif.

Dalam kehidupan bermasyarakat pasti akan menemukan keberagaman. Dalam keberagaman tersebut sering kali muncul berbagai gesekan kecil. Bahkan salah satunya dapat menciptakan konflik horizontal. Hal tersebut disebabkan oleh kesadaran untuk saling menghargai dan menghormati perbedaan yang masih perlu untuk ditingkatkan, meskipun boleh jadi ada pihak ketiga yang membuat suasana menjadi semakin panas. Dalam tulisan “Min Adab Al Khilaf wa at-Ta'amul Ma'a al Mukhalif”, Prof. Hani bin Abdullah al-Jabir menjelaskan secara detail tentang kaidah-kaidah utama dalam menghadapi perbedaan pendapat. Bersikap dalam menghadapi perbedaan pendapat menjadi sangat penting, karena kondisi saat ini telah muncul di dunia Islam berupa fanatisme berlebihan dari kelompok radikal dan fundamental. Sikap apriori yang diperlihatkan kepada pihak yang berbeda, sebagiannya berujung pada tindakan anarkisme. Seperti perusakan atau pembakaran tempat ibadah hingga penganiayaan. Melihat kondisi demikian, Prof. Hani, sangat menyayangkan peristiwa tersebut. Kaidah pertama yang ia tekankan adalah bersikap proporsional. Perbedaan tidak akan menimbulkan konflik apabila tidak diiringi dengan sentimen dan kebencian. “...Tiada berselisih orang-orang yang telah diberi al-Kitab kecuali sesudah 
datang pengetahuan kepada mereka, karena kedengkian (yang ada) di antara mereka..." (QS. Ali Imran [3]: 19. Ia mengutip pendapat Ibnu Taimiyah, tentang perintah berbuat adil dan proporsional kepada lawan, sebagaimana tertulis dalam Surah al-Maidah (5): 8 berikut ini:

Masalah sosial (urusan muamalah) mendapatkan perhatian yang begitu besar dalam agama Islam (ayat al-Qur'an maupun Hadits). Al-Qur'an menjelaskan berbagai pengetahuan, termasuk pendidikan etika sosial secara baik kepada seluruh manusia. Dalam al-Qur'an surat at-Taubah (9): 71, banyak dijelaskan pendidikan etika sosial berikut ini:

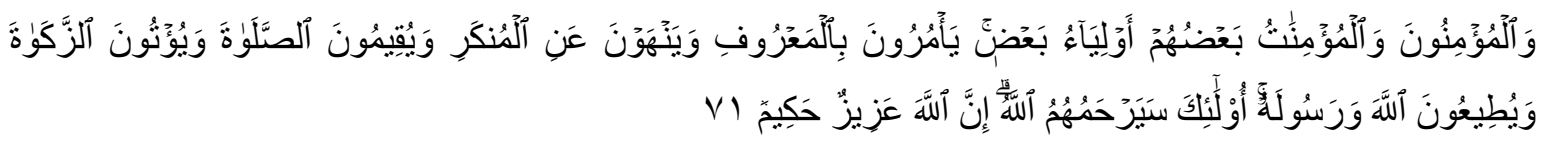

Dan orang-orang yang beriman, lelaki dan perempuan, sebahagian mereka (adalah) menjadi penolong bagi sebahagian yang lain. Mereka menyuruh (mengerjakan) yang ma'ruf, mencegah dari yang munkar, mendirikan shalat, menunaikan zakat dan mereka taat pada Allah dan RasulNya. Mereka itu akan diberi rahmat oleh Allah; sesungguhnya Allah Maha Perkasa lagi Maha Bijaksana (QS. At-Taubah [9]: 71)

Dalam tafsir al-Maraghi, disebutkan auliya dari kata al-walayah (mengasihi) lawan dari al-'adawah (memusuhi), dan mencakup mengasihi dengan pertolongan, dengan persaudaraan dan dengan kecintaan. Pada masa Nabi, para istri beliau dan para istri sahabatnya keluar bersama tentara untuk menyediakan air dan makanan, mendorong mereka untuk ikut berperang dan membangkitkan semangat orang yang kalah. Dalam menggambarkan kaum muslimin, Allah berfirman ba'duhum auliya'u ba'din, sebagian mereka adalah menjadi penolong bagi sebagian yang lain. Sebab diantara kaum mukminin terdapat rasa persaudaraan, kecintaan, saling menolong dan saling mengasihi, sehingga Nabi Muhammad SAW menyerupakan kesatuan mereka dengan tubuh yang satu dan bangunan yang sebagiannya menguatkan sebagian yang lain. Disamping itu, kaum muslimin juga saling tolong-menolong dalam menegakkan kebenaran dan keadilan serta meninggikan kalimat Allah SWT (Al-Maraghi, 2010).

Al-qur'an mendorong umat Islam untuk bersatu menjadi umat yang kuat secara aqidah, budaya, hukum, ekonomi, dan akhlak, dan menjalin berhubungan kemanusiaan atas dasar saling gotong royong dan bekerjasama, mengontrol dan menekan hal-hal yang menimbulkan perpecahan. Al-Qur'an telah jelas memerintahkan kita untuk menjaga persatuan dan kesatuan, yang didalamnya terdapat gotong royong serta saling bekerjasama karena merupakan saudara, sebagaimana disebutkan dalam QS. Ali Imran (3): 103 sebagai berikut: 
Tafsir al-Mishbah, menafsirkan ayat di atas dengan diawali kata i’tashimū (اعتصموا) terambil dari kata 'ashama (عصم) yang bermakna menghalangi. Penggalan ayat ini mengandung perintah untuk berpegang kepada tali Allah SWT yang berfungsi menghalangi seseorang terjatuh. Kata habl (حبل) yang berarti tali adalah apa yang digunakan untuk mengikat sesuatu guna mengangkatnya ke atas atau menurunkannya ke bawah agar sesuatu itu tidak terlepas atau terjatuh. Menurut Fakhruddin ar-Razi, setiap orang yang berjalan pada jalan yang sulit khawatir tergelincir jatuh, tetapi jika dia berpegang teguh pada tali yang terulur pada kedua ujung jalan yang dilaluinya, dia akan merasa aman dan tidak terjatuh, apalagi jika tali tersebut kuat dan cara memegangnnya pun kuat. Yang memilih tali yang rapuh atau tidak berpegang teguh, walaupun talinya kuat kemungkinan juga akan tergelincir sebagaimana dialami oleh banyak orang. Tali yang dimaksud dalam ayat ini adalah ajaran agama atau al-Qur'an. Kemudian dalam ayat ini juga menunjukkan betapa kuat jalinan kasih sayang dan persatuan mereka karena yang diharmoniskan Allah bukan hanya langkah-langkah tetapi hati. Apabila hati telah menyatu, segala sesuatu menjadi ringan dipikul dan segala kesalahpahaman (jika seandainya muncul), maka akan mudah diselesaikan. Memang, yang penting adalah kesatuan hati umat bukan kesatuan organisasi atau kegiatannya. Kata ikhwânâ disini diartikan yang dipersatukan hatinya oleh Allah SWT itu merasa sama dengan orang lain. Yang ringan sama mereka dijinjing dan yang berat sama-sama dipikul bersama. Sakit saudaranya samasama dirasakan dan kegembiraanpun dinikmati bersama. Karena persaudaraan yang terjalin antar sesama mukmin bukan hanya karena persamaan iman saja, tetapi juga "bagaikan" atas dasar persaudaraan seketurunan (Shihab, 2005).

\section{SIMPULAN}

Pembelajaran kooperatif merupakan model pembelajaran dengan menggunakan sistem pengelompokkan/tim kecil, yaitu antara 4 sampai 6 orang yang mempunyai latar belakang kemampuan akademik, jenis kelamin, ras, atau suku yang berbeda (heterogen. Dalam pembelajaran kooperatif akan memunculkan tanggung jawab individu terhadap kelompok dan keterampilan interpersonal dari setiap anggota kelompok. Setiap individu akan saling membantu, bekerjasama dan berdiskusi.

Adapun term-term al-qur'an yang berhubungan dengan kecerdasan sosial dalam pembelajarn kooperatif yaitu 'Aqala, Dzakara, Fakkara, Dabbara, Faqaha, dan Bashara. Adapun term yang berhubungan dengan Interaksi Sosial yaitu Ta'aruf, Ta'afuf, dan Mujadalah. Selanjutnya isyarat al-Qur'an yang berhubungan dengan Kecerdasan Sosial 
dapat ditemukan pada surat ad-Dhuha (93): 6-11 dan al-Baqarah (2): 177. Term yang berhubungan dengan Pembelajaran yaitu Allama-yu'allimu. Term yang berhubungan dengan kooperatif yaitu Ta'awun dan Musyawaroh. Dan isyarat al-Qur'an yang berhubungan dengan Pembelajaran Kooperatif terdapat dalam QS. Al-A'raf (7): 103 dan ayat al-A'raf (7): 85.

Kecerdasan sosial perpsektif al-Quran bukan hanya menjelaskan tentang bagaimana kemampuan manusia berhubungan dengan manusia lainnya (Hablum minannas), tetapi lebih fundamental lagi bahwa dari berhubungan baik dengan orang lain bertujuan untuk mencari ridho Allah SWT (Hablum minallah). Ketika seseorang memiliki kecerdasan sosial yang tinggi, maka segala perbuatan baiknya kepada orang lain diniatkan untuk mencari ridho Allah SWT. Dua dimensi yaitu dimensi religius dan dimensi sosial harus diaplikasikan dan diimplementasikan dalam kehidupan bermasyarakat.

\section{DAFTAR PUSTAKA}

Al-Maraghi, A. M. (2010). Tafsir al-Maraghi (tej. Juz 10). Semarang: PT. Thoha Putera.

Alim, A. (2014). Tafsir Pendidikan Islam. Jakarta: AMP Press.

Azzet, A. M. (2010). Mengembangkan Kecerdasan Sosial Bagi Anak. Yogyakarta: Katahati.

Charisma, M. C. (1991). Tiga Aspek Kemukjizatan Al-Qur'an. Surabaya: Bina Ilmu.

Faisal. (2016). Kecerdasan Intelektual Rasulullah SAW Perspektif Hadits. Jurnal Ulunnuha, 6(2).

Irawan, P. (2000). Logika dan Prosedur Penelitian: Pengantar Teori dan Panduan Praktis Penelitian Sosial bagi Mahasiswa dan Peneliti. Jakarta: STIA-LAN.

Nasution, S. (1995). Asas-asas Kurikulum. Jakarta: Bumi Aksara.

Prawira, P. A. (2013). Psikologi Pendidikan dalam Perspektif Baru. Yogyakarta: Ar-Ruzz Media.

Rasyid, M. A. (2017). Hadits-Hadits Tarbawi: Teori dan Praktik Pendidikan Sesuai Hadits Nabi Muhammad SAW. Yogyakarta: DIVA Press.

Safaria, T. (2005). Interpersonal Intelligence: Metode Pengembangan Kecerdasan Interpersonal Anak. Yogyakarta: Penerbit Amara Books.

Sagala, S. (2003). Konsep dan Makna Pembelajaran. Bandung :Alfa Beta.

Sarnoto, A. Z. (2017). Aspek Kemanusiaan Dalam Pembelajaran Humanistik Pada Anak Usia Dini. Profesi, 6(1), 108-114. https://jurnal.pmpp.or.id/index.php/profesi 
Sarnoto, A. Z. (2019). Dinamika Pendidikan Islam (1st ed., Vol. 1). Jakarta; PTIQ Press.

Sarnoto, A. Z., \& Andini, D. (2017). Sikap sosial dalam kurikulum 2013. MADANI Institute, 6(1), 59-70.

Sarnoto, A. Z., \& Rahmawati, S. T. (2020). Kecerdasan Emosional Dalam Perspektif AlQur'an. Statement, 10(1), 17-30.

https://jurnal.pmpp.or.id/index.php/statement/article/view/17

Shihab, M. Q. (2005). Tafsir Al Misbah, Pesan, Kesan dan Keserasian Al Quran (IV). Jakarta: Lentera Hati.

Sukmadinata, N. S. (2010). Metode Penelitian Pendidikan. Bandung: remaja Rosyda Karya.

Usman, M. B. (2002). Metode Pembelajaran Agama Islam. Jakarta: Ciputat Press.

Wehmeier, S. (2010). Oxford Advanced Learner's Dictionary. New York: Oxford University Press. 